\title{
Does involvement in food preparation track from adolescence to young adulthood and is it associated with better dietary quality? Findings from a 10-year longitudinal study
}

\author{
Melissa N Laska*, Nicole I Larson, Dianne Neumark-Sztainer and Mary Story \\ School of Public Health, Division of Epidemiology and Community Health, University of Minnesota, \\ 1300 S. 2nd Street - Suite 300, Minneapolis, MN 55454, USA
}

Submitted 2 May 2011: Accepted 18 0ctober 2011: First published online 29 November 2011

\begin{abstract}
Objectives: To examine whether involvement in food preparation tracks over time, between adolescence (15-18 years), emerging adulthood (19-23 years) and the mid-to-late twenties (24-28 years), as well as 10-year longitudinal associations between home food preparation, dietary quality and meal patterning.

Design: Population-based, longitudinal cohort study.

Setting: Participants were originally sampled from Minnesota public secondary schools (USA).

Subjects: Participants enrolled in Project EAT (Eating Among Teens and Young Adults)-I, EAT-II and EAT-III ( $n$ 1321).

Results: Most participants in their mid-to-late twenties reported an enjoyment of cooking ( $73 \%$ of males, $80 \%$ of females); however, few prepared meals including vegetables most days of the week ( $24 \%$ of males, $41 \%$ of females). Participants in their mid-to-late twenties who enjoyed cooking were more likely to have engaged in food preparation as adolescents and emerging adults $(P<0 \cdot 01)$; those who frequently prepared meals including vegetables were more likely to have engaged in food preparation as emerging adults $(P<0 \cdot 001)$, but not as adolescents. Emerging adult food preparation predicted better dietary quality five years later in the mid-to-late twenties, including higher intakes of fruit, vegetables and dark green/orange vegetables, and less sugar-sweetened beverage and fast-food consumption. Associations between adolescent food preparation and later dietary quality yielded few significant results.

Conclusions: Food preparation behaviours appeared to track over time and engagement in food preparation during emerging adulthood, but not adolescence, was associated with healthier dietary intake during the mid-to-late twenties. Intervention studies are needed to understand whether promoting healthy food preparation results in improvements in eating patterns during the transition to adulthood.
\end{abstract}

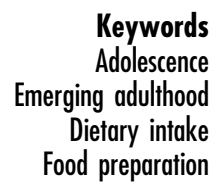

Obesity and poor dietary intake are major public health concerns $^{(1,2)}$. Nearly half of US adults report eating three or more commercially prepared meals each week ${ }^{(3)}$ and consumption of fast food is high ${ }^{(4)}$. Compared with meals prepared at home, commercially prepared meals contain more energy, saturated fat, $\mathrm{Na}$ and cholesterol, as well as lower levels of fibre and $\mathrm{Ca}^{(5)}$. Adolescents and young adults are among the most frequent consumers of awayfrom-home meals and many currently fail to meet national recommendations for health, such as the Dietary Guidelines for Americans ${ }^{(6-8)}$. Effective promotion of healthy dietary practices during adolescence and young adulthood is needed, as these are critical years during which long-term behaviour patterns are beginning to be established and the health behaviours engaged in during these life stages are predictive of long-term health ${ }^{(6)}$.

Previous research indicates that contextually related factors, including home food environments and home eating behaviours, may have an important impact on youth and adult dietary patterns ${ }^{(9-14)}$. Cross-sectional findings from Project EAT (Eating Among Teens and Young Adults), a large, diverse cohort of youth, indicate that engaging in home food preparation activities during early-to-mid adolescence (11-18 years of age) and emerging adulthood (19-23 years) is associated with healthier dietary intake ${ }^{(15,16)}$. Furthermore, nutrition promotion interventions targeting home food preparation skills are well received across a range of age groups and may yield 
changes in nutrition knowledge, attitudes, skills and some eating behaviours, like fruit/vegetable consumption ${ }^{(17-21)}$.

The adolescent and emerging adult years are viewed as formative periods during which long-term eating behaviours are adopted and maintained, and consequently influence long-term health ${ }^{(6)}$. However, little longitudinal research to date has examined the extent to which involvement in food preparation, particularly during adolescence and emerging adulthood, predicts future involvement in food preparation and more healthful dietary intake over time ${ }^{(22)}$. The current study addresses these gaps in the literature. The first study aim was to examine whether involvement in food preparation activities as an adolescent (age 15-18 years) is associated with food preparation as an emerging adult (age 19-23 years), as well as the extent to which these behaviours are associated with food preparation and enjoyment of cooking during the mid-to-late twenties (age 24-28 years). The second aim was to examine how adolescent and emerging adult home food preparation is associated with dietary quality and meal patterning 5-10 years later, in the mid-to-late twenties.

\section{Methods}

Data were drawn from Projects EAT-I, -II and -III, a three-wave, population-based study that examined dietary intake and weight-related factors among adolescents and young adults. The sample for the present analyses included 565 males and 756 females who completed surveys at EAT-I (mean age $=15 \cdot 8(\mathrm{sD} 0 \cdot 8)$ years), EAT-II $(20 \cdot 4(\mathrm{sD} 0 \cdot 8)$ years $)$ and EAT-III $(26 \cdot 2(\mathrm{SD} 0 \cdot 7)$ years $)$. For EAT-I (Time 1), thirty-one public middle schools and high schools in three school districts in the Minneapolis/ St. Paul metropolitan area of Minnesota participated in the study. Schools and school districts serving socioeconomically and racially/ethnically diverse communities were invited to participate in the study. Student survey and anthropometric data were collected within health, physical education and science classrooms during the 1998-1999 academic year. Trained research staff distributed the surveys within school classes for students to complete and assessed height and weight within a private area during the 1998-1999 academic year ${ }^{(23,24)}$.

Five years later (2003-2004), for EAT-II (Time 2), original participants were mailed follow-up surveys to examine changes in weight behaviours as they progressed through adolescence into emerging adulthood ${ }^{(25,26)}$. EAT-III (Time 3) was designed to follow up participants in 2008-2009 as they progressed through their mid-to-late twenties. At Time 3, participants were mailed survey invitation letters providing the web address and a unique password for completing the EAT-III survey online and an $\mathrm{FFQ}^{(27,28)}$.

The current analysis includes only participants who were in high school at EAT-I, in order to capture the unique life changes between mid adolescence (EAT-I), emerging adulthood (EAT-II) and the mid-to-late twenties (EAT-III). Among high-school students in EAT-I, the response rate at Time 2 among those who could be contacted was $68 \%$. Among those who could be contacted at Time 3, the response rate was $68 \%$ (53\% of the Time 1 high-school sample). The University of Minnesota's Institutional Review Board approved all study protocols.

\section{Survey measures}

\section{Food preparation practices}

Food preparation practices were assessed in all study waves. Additionally, measures were modified over time to assess developmentally appropriate information for the different age groups being assessed.

At Time 1, measures of adolescent involvement in household food tasks were developed for the EAT-I survey ${ }^{(15)}$. Frequency of helping prepare food for dinner was assessed by asking: 'In the past week, how many times did you help prepare food for dinner?' Response categories were never, 1 or 2 times, 3 or 4 times, 5 or 6 times, and 7 times.

Five years later, additional survey items were developed for EAT-II and pretested with emerging adults. To assess additional behaviours related to home food preparation that were age-appropriate for emerging adults, participants were asked how often they performed five behaviours over the past 12 months: (i) bought fresh vegetables; (ii) wrote a grocery list; (iii) prepared a green salad; (iv) prepared a dinner with chicken, fish or vegetables; and (v) prepared an entire dinner for two or more people. Response categories were never, 1 or 2 times, 4 or 5 times, monthly, weekly or daily. As in previous research, these items were used to form a summary food preparation frequency score $^{(16)}$. To form this score, the frequency of each behaviour was assigned a score of $1,2,3,4,5$ or 6 , such that 1 represented 'never' and 6 represented 'daily' involvement in preparation. When the scores for each preparation behaviour were summed, food preparation frequency scores ranged from 5 to 30 (with higher scores indicative of more food preparation) and had a Cronbach's $\alpha$ of $0 \cdot 80$.

In EAT-III, participants were asked 'During the past month, how often have you prepared a meal that included vegetables?' with the response categories including never, one time, a few times, weekly, a few times per week or most days of the week. Participants were also asked the extent to which they agreed with the following statement: 'I like to cook' (hereafter referred to as 'enjoyment of cooking'). Possible response options were strongly agree (hereafter referred to as 'greatly enjoy'), somewhat agree ('somewhat enjoy'), somewhat disagree ('somewhat dislike') and strongly disagree ('strongly dislike').

\section{Dietary behaviours}

Dietary intake. For EAT-III, data derived from the Willett semi-quantitative FFQ (2007 grid form) was used to assess 
usual past year intake of fruit, vegetables, whole grains, Ca-rich foods and sugar-sweetened beverages (i.e. sodas, sports drinks, punch, lemonade, sugared ice tea) ${ }^{(29)}$. Given the emphasis on specific types of vegetables in national recommendations for health ${ }^{(8)}$, these data were also used to assess intake of dark green/orange vegetables (i.e. broccoli, carrots, yams/sweet potatoes, dark orange squash, kale, mustard greens, chard, spinach, Romaine or leaf lettuce, bok choy), in addition to participants' total vegetable intake. Daily servings were defined as the equivalent of one-half cup for fruits (excluding fruit juice) and vegetables (excluding French fries) and $16 \mathrm{~g}$ for whole grains. A serving of sugar-sweetened beverages was defined as the equivalent of one glass, bottle or can. The FFQ was also used to assess usual daily intakes of total energy (calories), total fat (percentage of total energy) and saturated fat (percentage of total energy). Nutrient intakes were determined in 2009 by the Nutrition Questionnaire Service Center at the Harvard School of Public Health using a specially designed database, primarily based on the US Department of Agriculture's Nutrient Database for Standard Reference (release 19). Previous studies have examined the reliability and validity of intake estimates ${ }^{(30,31)}$. A youth form of the FFQ was used to assess dietary intake at EAT-I and EAT-II ${ }^{(32,33)}$.

Meal frequencies. Meal frequencies were also assessed using the EAT-I, -II and -III surveys. Participants were asked how often they ate breakfast, lunch and dinner during the past week (response categories included never, 1-2 d, 3-4 d, 5-6 d and every day) and how often they ate at a fastfood restaurant (like McDonald's, Burger King, Hardee's, etc.) in the past week (response categories included never, 1-2 times, 3-4 times, 5-6 times, 7 times and $\geq 7$ times).

\section{Covariates}

Sex, race/ethnicity, parental employment status and socioeconomic status (SES) were based on self-report on the baseline EAT survey. SES was based primarily on reports of parental educational level, defined by the higher level of either parent during the administration of the EAT-I survey, and has been described in detail elsewhere ${ }^{(23)}$. In EAT-II, participants reported their current living situation (e.g. living in a college or university residence hall). Participants also reported age, employment status, relationship status and other demographic characteristics in EAT-III.

\section{Analysis}

Descriptive statistics were calculated to examine enjoyment of cooking and involvement in food preparation among young adult men and women at EAT-III as well as relationships between food preparation practices in adolescence (EAT-I) and emerging adulthood (EAT-II). Gender-stratified linear regression models were used to explore whether food preparation practices during adolescence and emerging adulthood were related to food preparation during the mid-to-late twenties (EAT-III). Finally, gender-stratified linear regression models were used to examine 5-year and 10-year longitudinal associations between food preparation practices and outcomes of interest (i.e. dietary intake, meal frequencies) while controlling for baseline dietary behaviours. All regression models included young adult age, race/ethnicity and SES. Models relating to emerging adult food preparation were additionally adjusted for living situations (i.e. living in a residence hall at EAT-II). Models related to adolescent food preparation adjusted for parental employment. Dietary intake outcomes were also adjusted for total energy consumption using the regression approach. All variables examined in regression models were standardized to allow for relative comparisons of strength between the observed associations. When the outcome variable of interest exhibited positive skewness, testing was carried out using the square root transformation. A 95\% confidence level was used to interpret the statistical significance of probability tests, corresponding to a $P$ value of $<0 \cdot 05$.

Because attrition from the baseline sample did not occur at random, the data were weighted using the response propensity method ${ }^{(34)}$. The weighting resulted in estimates representative of the demographic make-up of the original school-based sample, thereby allowing results to be more fully generalizable. Specifically, the weighted EAT-III sample was $55 \cdot 1 \%$ white, $15 \cdot 9 \%$ African American, $17 \cdot 6 \%$ Asian, $5 \cdot 5 \%$ Hispanic, $2 \cdot 2 \%$ Native American, and $3.7 \%$ mixed or other race/ethnicity. The weighted EAT-III sample is similar to that of the overall US population of 25-29-year-olds in 2007-2009, which was 59.5\% white, $13.5 \%$ African American, 5.2\% Asian, $11 \cdot 1 \%$ Hispanic (white), $0.9 \%$ American Indian or Alaskan Native, and $9 \cdot 8 \%$ other or two or more races ${ }^{(35)}$. The weighted EAT-III sample was well distributed across categories of SES: $36 \cdot 2 \%$ low or low-middle, $25 \cdot 8 \%$ middle and $38.0 \%$ upper-middle or high.

Additional details of the methodology of these propensity weights have been described elsewhere ${ }^{(28,36)}$. All analyses were conducted using the SAS statistical software package version 9·1 (2002-2003; SAS Institute Inc., Cary, NC, USA).

\section{Results}

\section{Descriptive characteristics}

A majority of participants ( $65 \%$ of males, $55 \%$ of females) were employed full time at EAT-III. About a quarter (27\% of males, $28 \%$ of females) were married or living with a domestic partner, while $33 \%$ of males and $42 \%$ of females were in a committed dating relationship. Approximately a third reported being parents (30\% of males, 37\% of females).

Descriptive characteristics of food preparation behaviours and enjoyment of cooking among participants in their mid-to-late twenties are presented in Table 1. More females (41\%) than males (24\%) reported that they prepare a meal with vegetables most days of the week. 
Most male and female participants reported they greatly or somewhat enjoy cooking.

\section{Five-year associations between food preparation} during adolescence and emerging adultbood

Food preparation during adolescence (EAT-I) was associated with food preparation in emerging adulthood (EAT-II; Table 2). Adolescents who helped prepare food for dinner at least 1-2 times weekly were more likely to engage in food preparation-related behaviours as emerging adults, such as buying fresh vegetables $(P<0 \cdot 001)$, writing a grocery list $(P<0 \cdot 001)$, preparing a dinner with chicken, fish or vegetables $(P=0 \cdot 01)$ and preparing an entire dinner for two or more people $(P<0 \cdot 001)$. Adolescent food preparation was not associated with preparing a green salad five years later in emerging adulthood.

\section{Longitudinal associations in food preparation behaviours}

Associations between food preparation during adolescence and emerging adulthood (EAT-I and -II) and food preparation in the mid-to-late twenties (EAT-III) are

Table 1 Food preparation and enjoyment of cooking among males and females in their mid-to-late twenties (Project EAT-III), Minneapolis/St. Paul metropolitan area, Minnesota, USA

\begin{tabular}{|c|c|c|}
\hline & $\begin{array}{c}\text { Males } \\
(n 565) \\
\%\end{array}$ & $\begin{array}{c}\text { Females } \\
(n 756) \\
\%\end{array}$ \\
\hline \multicolumn{3}{|c|}{$\begin{array}{l}\text { Frequency of preparing a meal including } \\
\text { vegetable(s) in the past month }\end{array}$} \\
\hline Never & $4 \cdot 7$ & $3 \cdot 0$ \\
\hline One time & $5 \cdot 9$ & $2 \cdot 8$ \\
\hline A few times & $26 \cdot 3$ & $15 \cdot 6$ \\
\hline Weekly & $15 \cdot 7$ & $12 \cdot 2$ \\
\hline A few times per week & $23 \cdot 6$ & $25 \cdot \overline{5}$ \\
\hline Most days & $23 \cdot 9$ & $40 \cdot 8$ \\
\hline \multicolumn{3}{|l|}{ Enjoyment of cooking } \\
\hline Greatly enjoy & $39 \cdot 5$ & $38 \cdot 9$ \\
\hline Somewhat enjoy & $33 \cdot 6$ & $40 \cdot 6$ \\
\hline Somewhat dislike & $18 \cdot 0$ & $13 \cdot 2$ \\
\hline Strongly dislike & $8 \cdot 8$ & $7 \cdot 3$ \\
\hline
\end{tabular}

EAT, Eating Among Teens and Young Adults. presented in Table 3. Helping to prepare food for dinner during adolescence was significantly associated with enjoyment of cooking ten years later among males and females $(P=0.003$ and $P<0 \cdot 001$, respectively). However, helping to prepare dinner as an adolescent was not significantly associated with frequency of preparing meals that included vegetables ten years later. Food preparation in emerging adulthood significantly predicted both liking to cook and more frequent preparation of meals with vegetables five years later for males and females in their mid-to-late twenties $(P<0 \cdot 001)$.

\section{Longitudinal associations between food preparation behaviours and dietary patterns}

Adjusting for baseline meal patterns, adolescent food preparation did not predict frequency of consuming breakfast, lunch, dinner or fast food during the mid-to-late twenties for either males or females (Table 4). In contrast, food preparation during emerging adulthood significantly predicted more frequent breakfast and lunch consumption, and less frequent fast-food intake among males and females in their mid-to-late twenties $(P<0 \cdot 05)$. For example, with every one standard deviation increase in the emerging adult food preparation frequency score $(5 \cdot 3$ units), breakfast frequency increased by $0 \cdot 24$ times/week $(0 \cdot 10$ standardized units) among males in their mid-to-late twenties. A five-unit increase in the food preparation frequency score would represent the difference between performing one of the five key food preparation behaviours (e.g. prepared a green salad; prepared a dinner with chicken, fish or vegetables; etc.) never $v$. performing the behaviour daily, with all other factors being equal.

As shown in Table 5, adolescent food preparation yielded few associations with dietary patterns ten years later. Males who frequently helped prepare food for dinner as adolescents tended to consume fewer vegetables $(\beta=-0 \cdot 17, P<0 \cdot 001)$ when they were in their mid-to-late twenties. Females who frequently helped prepare food for dinner as adolescents tended to consume fewer whole grains $(\beta=-0.09, P=0.03)$ in their mid-to-late twenties.

Table 2 Food preparation behaviours in emerging adulthood (EAT-II) by involvement in food preparation during adolescence (EAT-I), Minneapolis/St. Paul metropolitan area, Minnesota, USA

$\%$ of participants who report helping to prepare food for dinner as adolescents (in EAT-I)

\begin{tabular}{|c|c|c|c|}
\hline & \\
\hline & $\begin{array}{l}\text { Never }(n 420) \\
\%\end{array}$ & $\begin{array}{l}\text { At least } 1-2 \text { times in } \\
\text { past week }(n 892) \%\end{array}$ & $P$ value \\
\hline \multicolumn{4}{|c|}{$\begin{array}{l}\text { \% of participants who report engaging in food preparation-related } \\
\text { behaviours at least weekly as emerging adults (in EAT-II) }\end{array}$} \\
\hline Buying fresh vegetables & $19 \cdot 4$ & $33 \cdot 9$ & $<0.001$ \\
\hline Writing a grocery list & $12 \cdot 0$ & $21 \cdot 4$ & $<0.001$ \\
\hline Preparing a green salad & $29 \cdot 1$ & $28 \cdot 5$ & 0.83 \\
\hline Preparing a dinner with chicken, fish or vegetables & $44 \cdot 9$ & $52 \cdot 4$ & 0.01 \\
\hline Preparing an entire dinner for two or more people & $28 \cdot 5$ & $41 \cdot 0$ & $<0.001$ \\
\hline
\end{tabular}

EAT, Eating Among Teens and Young Adults. 
Table 3 Enjoyment of cooking and food preparation practices in the mid-to-late twenties (EAT-III), by food preparation practices five and ten years earlier (EAT-I and EAT-II), Minneapolis/St. Paul metropolitan area, Minnesota, USA

\begin{tabular}{|c|c|c|c|c|}
\hline & \multicolumn{4}{|c|}{ Young adulthood (EAT-III) } \\
\hline & \multicolumn{2}{|c|}{ Enjoyment of cooking } & \multicolumn{2}{|c|}{$\begin{array}{l}\text { Frequency of preparing meals } \\
\text { that include vegetables }\end{array}$} \\
\hline & $\beta$ & $P$ value & $\beta$ & $P$ value \\
\hline \multicolumn{5}{|l|}{ Males } \\
\hline \multicolumn{5}{|l|}{ Adolescence (EAT-I)* } \\
\hline $\begin{array}{l}\text { Frequency of helping to prepare food for dinner } \\
\text { Emerging adulthood (EAT-II)t }\end{array}$ & $0 \cdot 18$ & 0.003 & 0.06 & $0 \cdot 35$ \\
\hline \multicolumn{3}{|l|}{ Females } & 0.37 & $<0.001$ \\
\hline Adolescence (EAT-I)* & & & & \\
\hline $\begin{array}{l}\text { Frequency of helping to prepare food for dinner } \\
\text { Emerging adulthood (EAT-II)† }\end{array}$ & $0 \cdot 16$ & $<0.001$ & 0.06 & $0 \cdot 14$ \\
\hline Food preparation frequency score & $0 \cdot 24$ & $<0.001$ & 0.33 & $<0.001$ \\
\hline
\end{tabular}

EAT, Eating Among Teens and Young Adults.

Note: all models were adjusted for age at EAT-III, as well as race/ethnicity and socio-economic status.

*Models using EAT-I data were additionally adjusted for parental employment status. Coding of scores for 'frequency of helping to prepare food for dinner' ranged from 1 to 5 (reflecting five possible response options ranging from never to 7 times in the past week).

tModels using EAT-II data were additionally adjusted for living situation (i.e. living in residence hall at the time of EAT-II). Food preparation frequency scores were calculated as the sum of five food preparation frequency items included in the EAT-II survey: buying fresh vegetables; writing a grocery list; preparing a green salad; preparing a dinner with chicken, fish or vegetables; and preparing an entire dinner for two or more people. Scores ranged from 5 to 30 (with higher scores indicative of more food preparation).

Table 4 Adjusted associations between food preparation during adolescence (EAT-I) and emerging adulthood (EAT-II) and meal patterns during the mid-to-late twenties (EAT-III), Minneapolis/St. Paul metropolitan area, Minnesota, USA

\begin{tabular}{|c|c|c|c|c|c|c|c|c|}
\hline & \multicolumn{8}{|c|}{ Young adulthood (EAT-III) } \\
\hline & \multicolumn{2}{|c|}{$\begin{array}{c}\text { Breakfast } \\
\text { (times/week) }\end{array}$} & \multicolumn{2}{|c|}{$\begin{array}{c}\text { Lunch } \\
\text { (times/week) }\end{array}$} & \multicolumn{2}{|c|}{$\begin{array}{c}\text { Dinner } \\
\text { (times/week) }\end{array}$} & \multicolumn{2}{|c|}{$\begin{array}{c}\text { Fast food } \\
\text { (times/week) }\end{array}$} \\
\hline & $\beta$ & $P$ value & $\beta$ & $P$ value & $\beta$ & $P$ value & $\beta$ & $P$ value \\
\hline \multicolumn{9}{|l|}{ Males } \\
\hline \multicolumn{9}{|l|}{ Adolescence $($ EAT-I)* } \\
\hline $\begin{array}{l}\text { Frequency of helping to prepare food for dinner } \\
\text { Emerging adulthood (EAT-II) }+\end{array}$ & -0.05 & $0 \cdot 33$ & -0.03 & 0.61 & $-0 \cdot 10$ & 0.06 & -0.005 & 0.94 \\
\hline $\begin{array}{l}\text { Food preparation frequency score } \\
\text { Females }\end{array}$ & $0 \cdot 10$ & 0.03 & 0.09 & 0.05 & 0.03 & 0.44 & $-0 \cdot 14$ & 0.01 \\
\hline Adolescence (EAT-I)* & & & & & & & & \\
\hline $\begin{array}{l}\text { Frequency of helping to prepare food for dinner } \\
\text { Emerging adulthood (EAT-II) }+\end{array}$ & -0.02 & 0.66 & 0.01 & $0 \cdot 79$ & 0.0004 & 0.99 & -0.03 & 0.38 \\
\hline Food preparation frequency score & $0 \cdot 11$ & 0.007 & $0 \cdot 10$ & 0.01 & -0.01 & $0 \cdot 77$ & -0.09 & 0.01 \\
\hline
\end{tabular}

EAT, Eating Among Teens and Young Adults.

Note: all models were adjusted for age at EAT-III, as well as race/ethnicity, socio-economic status and baseline dietary variables (i.e. dietary intake).

*Models using EAT-I data were additionally adjusted for parental employment status. Coding of scores for 'frequency of helping to prepare food for dinner' ranged from 1 to 5 (reflecting five possible response options ranging from never to 7 times in the past week).

tModels using EAT-II data were additionally adjusted for living situation (i.e. living in residence hall at the time of EAT-II). Food preparation frequency scores were calculated as the sum of five food preparation frequency items included in the EAT-II survey: buying fresh vegetables; writing a grocery list; preparing a green salad; preparing a dinner with chicken, fish or vegetables; and preparing an entire dinner for two or more people. Scores ranged from 5 to 30 (with higher scores indicative of more food preparation).

Findings indicate more robust associations between food preparation in emerging adulthood and better dietary quality five years later. Males with higher food preparation frequency scores in emerging adulthood tended to consume more fruit, vegetables and dark green/orange vegetables in their mid-to-late twenties, as well as fewer sugar-sweetened beverages $(P \leq 0 \cdot 01)$. For example, among males, every one standard deviation increase in the food preparation frequency score was associated with an increase in energy-adjusted intake of fruit of $0 \cdot 15$ servings/d $(0 \cdot 10$ standardized units).
Females with higher emerging adult food preparation frequency scores consumed more fruit, vegetables, dark green/orange vegetables and whole grains, and had lower sugar-sweetened beverage and saturated fat consumption five years later $(P<0 \cdot 01)$.

\section{Discussion}

More than two-thirds of EAT-III participants, ages 24-28 years, reported that they enjoy cooking. Participants who 
Table 5 Adjusted associations between food preparation during adolescence (EAT-I) and emerging adulthood (EAT-II) and dietary intake during the mid-to-late twenties (EAT-III), Minneapolis/ St. Paul metropolitan area, Minnesota, USA

\begin{tabular}{|c|c|c|c|c|c|c|c|c|c|c|c|c|c|c|c|c|}
\hline & \multicolumn{16}{|c|}{ Young adulthood (EAT-III) } \\
\hline & \multicolumn{2}{|c|}{$\begin{array}{c}\text { Fruit } \\
\text { (servings/d) }\end{array}$} & \multicolumn{2}{|c|}{$\begin{array}{l}\text { Vegetables } \\
\text { (servings/d) }\end{array}$} & \multicolumn{2}{|c|}{$\begin{array}{c}\text { Dark green/orange } \\
\text { vegetables } \\
\text { (servings/d) }\end{array}$} & \multicolumn{2}{|c|}{$\begin{array}{l}\text { Ca-rich foods } \\
\text { (servings/d) }\end{array}$} & \multicolumn{2}{|c|}{$\begin{array}{l}\text { Whole grains } \\
\text { (servings/d) }\end{array}$} & \multicolumn{2}{|c|}{$\begin{array}{c}\text { Sugar-sweetened } \\
\text { beverages } \\
\text { (servings/d) }\end{array}$} & \multicolumn{2}{|c|}{$\%$ fat } & \multicolumn{2}{|c|}{$\%$ saturated fa } \\
\hline & $\beta$ & $P$ value & $\beta$ & $P$ value & $\beta$ & $P$ value & $\beta$ & $P$ value & $\beta$ & $P$ value & $\beta$ & $P$ value & $\beta$ & $P$ value & $\beta$ & $P$ value \\
\hline \multicolumn{17}{|l|}{ Males } \\
\hline \multicolumn{17}{|l|}{ Adolescence (EAT-I)* } \\
\hline $\begin{array}{l}\text { Frequency of helping to prepare } \\
\text { food for dinner }\end{array}$ & $-0 \cdot 03$ & 0.52 & $-0 \cdot 17$ & $<0.001$ & -0.04 & $0 \cdot 35$ & 0.06 & $0 \cdot 23$ & $0 \cdot 03$ & 0.57 & $0 \cdot 01$ & $0 \cdot 81$ & -0.005 & 0.92 & -0.02 & $0 \cdot 70$ \\
\hline \multicolumn{17}{|l|}{ Emerging adulthood (EAT-II)† } \\
\hline $\begin{array}{l}\text { Food preparation frequency score } \\
\text { Females }\end{array}$ & $0 \cdot 10$ & $<0.001$ & $0 \cdot 12$ & 0.003 & $0 \cdot 14$ & $<0.001$ & $-0 \cdot 03$ & 0.57 & 0.08 & $0 \cdot 08$ & $-0 \cdot 13$ & $0 \cdot 01$ & 0.04 & $0 \cdot 35$ & 0.004 & 0.93 \\
\hline \multicolumn{17}{|l|}{ Adolescence (EAT-I)* } \\
\hline $\begin{array}{l}\text { Frequency of helping to prepare } \\
\text { food for dinner }\end{array}$ & 0.07 & 0.06 & -0.05 & $0 \cdot 22$ & -0.06 & $0 \cdot 18$ & $-0 \cdot 03$ & $0 \cdot 41$ & -0.09 & 0.03 & 0.02 & 0.54 & -0.03 & $0 \cdot 43$ & -0.03 & 0.46 \\
\hline \multicolumn{17}{|l|}{ Emerging adulthood (EAT-II)† } \\
\hline Food preparation frequency score & $0 \cdot 18$ & $<0.001$ & $0 \cdot 20$ & $<0.001$ & $0 \cdot 19$ & $<0.001$ & -0.03 & $0 \cdot 47$ & $0 \cdot 11$ & 0.003 & $-0 \cdot 16$ & $<0.001$ & -0.04 & $0 \cdot 36$ & $-0 \cdot 12$ & 0.007 \\
\hline
\end{tabular}

EAT, Eating Among Teens and Young Adults.

Note: all models were adjusted for age at EAT-III, as well as race/ethnicity, socio-economic status and baseline dietary variables (i.e. dietary intake).

${ }^{*}$ Models using EAT-I data were additionally adjusted for parental employment status. Coding of scores for 'frequency of helping to prepare food for dinner' ranged from 1 to 5 (reflecting five possible response options ranging from never to 7 times in the past week).

+Models using EAT-II data were additionally adjusted for living situation (i.e. living in residence hall at the time of EAT-II). Food preparation frequency scores were calculated as the sum of five food preparation frequency items included in the EAT-II survey: buying fresh vegetables; writing a grocery list; preparing a green salad; preparing a dinner with chicken, fish or vegetables; and preparing an entire dinner for two or more people. Scores ranged from 5 to 30 (with higher scores indicative of more food preparation). 
enjoyed cooking in their mid-to-late twenties were significantly more likely to have been engaged in food preparation activities as adolescents (ages 15-18 years in EAT-I) and emerging adults (ages 19-23 years in EAT-II). However, many young people in their mid-to-late twenties may not be routinely utilizing cooking skills for healthy home food preparation; for example, few participants, especially young men, reported preparing a meal that included a vegetable on most days of the week (24\% of males, $41 \%$ of females). In addition, food preparation during emerging adulthood was associated with better dietary quality during the mid-to-late twenties, including higher intakes of fruit, vegetables, dark green/orange vegetables, whole grains (females only), lower intakes of sugar-sweetened beverages and saturated fat (females only), more routine consumption of breakfast and lunch, and less frequent fast-food consumption. Although the magnitude of the effect estimates indicated here were not extremely large, the consistency and robustness of these findings point to the potential role of emerging adult food preparation as one of numerous significant factors influencing young adults' dietary intake and suggest a need for nutrition educators to work with emerging adults in building skills around home food preparation and meal planning.

In contrast, associations between adolescent food preparation and dietary factors during the mid-to-late twenties were largely null. However, adolescent food preparation was associated with a lower consumption of vegetables (males only) and whole grains (females only) among those in their mid-to-late twenties. Fruit, Ca-rich foods, sugar-sweetened beverages, total fat and saturated fat intakes among those in their mid-to-late twenties were not associated with adolescent food preparation. It is possible that adolescents were participating in home food preparation due to a more limited parental involvement and/or presence in the home, factors that could yield independent, negative associations with long-term dietary patterns. Although we were able to control for parental employment in our models examining adolescent food preparation, we were not able to control for other characteristics, such as family structure and/or number of adults in the household. Such factors may play an influential role in the relationship between food preparation and dietary intake; for example, adolescents living in single-parent households may help prepare food for dinner more frequently than those living in two-parent households, but may be at additional risk for poor dietary intake later in life due to a variety of socio-economic and/or family-related factors that are not attributable to home food preparation.

To our knowledge, the present study is the first of its kind to examine longitudinal associations between home food preparation and dietary outcomes during the transition from adolescence to young adulthood. Our study utilizes unique data from a large, diverse cohort of youth followed over a decade. Despite these important strengths, a limitation of the study is a lack of consistent measures of food preparation across all three time points. Food preparation measures included in EAT-II (i.e. among emerging adults) were rather robust and included numerous behavioural dimensions, including buying fresh vegetables; writing a grocery list; preparing a green salad; preparing a dinner with chicken, fish or vegetables; and preparing an entire dinner for two or more people. Together, these dimensions may reflect many important elements of a sustainable behavioural pattern. In contrast, we have a more limited ability to characterize adolescent food preparation (i.e. one survey item on the frequency of helping prepare food for dinner). Although these differences between the EAT-I and EAT-II surveys were developmentally appropriate, it is important to note these differences in interpreting our results. Given that we have a limited ability to characterize adolescent food preparation, it is possible that our estimates of associations between adolescent food preparation and later dietary intake may be subject to an increased degree of imprecision and error, thus making it less likely that we would be able to detect a significant association if one did exist.

Overall, the present study addresses an issue that has not yet been the topic of much rigorous scientific research ${ }^{(22)}$, but may be critical in understanding the determinants of excess weight gain among young adults. Recent findings from Laska et $a l^{(37)}$ indicate that establishing healthy mealtimes at home may be particularly challenging for emerging adults; in a study of participants aged 18-23 years using real-time data collection, approximately half or more of eating occasions occurred alone, while engaging in other activities (e.g. watching television, using a computer) and/or with little to no advanced planning. Although many documented eating occasions among these emerging adults consisted of a wide range of highly processed, energy-dense, convenience products, findings from that research also suggested that more traditional meal settings (i.e. eating with other people in the absence of distractions such as television) resulted in more structured mealtimes and healthier food choices ${ }^{(37)}$. Thus, promoting more structured and traditional mealtimes may be a valuable component of nutrition promotion for emerging adults, and it may be important for future research and health promotion efforts to target at-home food preparation as an integral component of these healthy, structured mealtimes.

Declines in secondary school-based home economics courses are often cited as a reason why many young adults lack cooking skills and do not engage in home food preparation $^{(38)}$. Somewhat surprisingly, recent national survey data indicate that the proportion of US secondaryschool students enrolled in Family and Consumer Science programmes has not changed since the $1950 \mathrm{~s}^{(39)}$. However, food preparation and meal planning have traditionally been only one part of the Family and Consumer Science curriculum, and it is very possible that the food-related 
content of these programmes has declined significantly over time. Further research is needed to explore what young people are learning about food preparation within schools and other settings. While it may be important to introduce cooking skills to young people early on, it is also likely that these courses alone are insufficient to equip youth in beginning a lifelong habit of healthy home food preparation. Overall, more intensive efforts may be needed to not only help young people develop skills to prepare healthy meals at home, but also to develop an enthusiasm for healthful lifestyle habits over time and better cope with the obesogenic environments in which they live. Efforts to do so need to be targeted not only within schools, but also within family, home and community settings. Although the findings from our study do not indicate that adolescent food preparation is associated with improved dietary intake later in life, our work does provide evidence for tracking of food preparation-related behaviours over time; therefore, engaging adolescents in healthy food preparation may result in better home food preparation habits later on (as well as enjoyment of cooking), which in turn may have a positive impact on dietary outcomes.

Overall, rigorous behavioural intervention research is needed to understand how to successfully promote young adult health. Today, most young adults across the USA fail to meet the national dietary recommendations for health. For example, data from the 2009 Behavioral Risk Factor Surveillance System indicate that only $20 \%$ of 18-24-year-olds and 25\% of 25-34-year-olds consume vegetables three or more times daily ${ }^{(40)}$. Our findings indicate that most participants in their mid-to-late twenties are not engaged in healthy home food preparation on most days of the week, particularly young men. This is highly consistent with previous research, indicating that young men tend to be particularly disengaged from the process of cooking and/or preparing food at home ${ }^{(15,16,41,42)}$. It is important that future intervention research explores the ways in which we can more effectively connect young adults, particularly young men, with their food and engage them in healthy meal preparation at home in enjoyable ways, as well as exploring the potential dietary impacts of such behavioural changes.

The transition from adolescence to young adulthood is a stage of dramatic lifestyle transitions and an age at which many young people do not engage in healthful behaviours. Our findings suggest that engaging adolescents in food preparation activities may increase the likelihood that they will continue with these activities during the transition out of their parents' homes and into independent lifestyles, but there are also many barriers that may be challenging throughout the transition from adolescence to young adulthood ${ }^{(43)}$. Effective strategies are needed to aid and support young adults in engaging in healthy diet-related practices, such as frequent healthy home food preparation, during this critical transition period. Our findings suggest that emerging adulthood, rather than adolescence, may be a particularly important period during which healthy lifestyle habits need to be established as part of an individual's independent lifestyle in order to be adopted in the long term.

In summarizing the most important food environment changes needed in order to support individuals in meeting the Dietary Guidelines for Americans, the first necessary change cited by the 2010 Dietary Guidelines Advisory Committee was to 'improve nutrition literacy and cooking skills, including safe food handling skills, and empower and motivate the population ... to prepare and consume healthy foods at home ${ }^{(44)}$. Overall, the findings from the present study and others suggest that the transition to young adulthood may be an important age for acquiring and reinforcing these skills, and for promoting positive advances to long-term diet-related health outcomes. Additional research is needed to confirm these findings.

\section{Acknowledgements}

The project described was supported by Grant Number R01HL084064 from the National Heart, Lung, and Blood Institute. Additional salary support was also provided by Grant Number K07CA126837 from the National Cancer Institute. The content is solely the responsibility of the authors and does not necessarily represent the official views of the National Heart, Lung, and Blood Institute or the National Cancer Institute. The authors have no conflicts of interest to declare. M.N.L. was responsible for leading the development of the research question and writing the manuscript. N.L. led the data analysis. D.N.S. acquired funding, directed the overall study implementation and data collection, and designed Project EAT. M.S. contributed on the design and implementation of Project EAT. All authors contributed to the interpretation of findings and provided critical revisions to the manuscript.

\section{References}

1. Flegal KM, Carroll MD, Ogden CL et al. (2010) Prevalence and trends in obesity among US adults, 1999-2008. JAMA 303, 235-241.

2. Ogden CL, Carroll MD, Curtin LR et al. (2010) Prevalence of high body mass index in US children and adolescents, 2007-2008. JAMA 303, 242-249.

3. Kant AK \& Graubard BI (2004) Eating out in America, 1987-2000: trends and nutritional correlates. Prev Med 38, 243-249.

4. Larson NI, Neumark-Sztainer DR, Story MT et al. (2008) Fast food intake: longitudinal trends during the transition to young adulthood and correlates of intake. $J$ Adolesc Health 43, 79-86.

5. Guthrie JF, Lin BH \& Frazao E (2002) Role of food prepared away from home in the American diet, 1977-78 versus 1994-96: changes and consequences. J Nutr Educ Behav 34, 140-150.

6. Nelson M, Story M, Larson N et al. (2008) Emerging adulthood and college-aged youth: an overlooked age for weight-related behavior change. Obesity (Silver Spring) 16, 2205-2211. 
7. Laska MN, Larson NI, Neumark-Sztainer D et al. (2010) Dietary patterns and home food availability during emerging adulthood: do they differ by living situation? Public Health Nutr 13, 222-228.

8. US Department of Health and Human Services \& US Department of Agriculture (2010) Dietary Guidelines for Americans, 2010. Washington, DC: US Government Printing Office.

9. Fulkerson JA, Nelson MC, Lytle L et al. (2008) The validation of a home food inventory. Int $J$ Behav Nutr Phys Act 5, 55.

10. Campbell KJ, Crawford DA, Salmon J et al. (2007) Associations between the home food environment and obesity-promoting eating behaviors in adolescence. Obesity (Silver Spring) 15, 719-730.

11. Hanson NI, Neumark-Sztainer D, Eisenberg ME et al. (2005) Associations between parental report of the home food environment and adolescent intakes of fruits, vegetables and dairy foods. Public Health Nutr 8, 77-85.

12. Cullen KW, Baranowski T, Owens E et al. (2003) Availability, accessibility, and preferences for fruit, 100\% fruit juice, and vegetables influence children's dietary behavior. Health Educ Behav 30, 615-626.

13. Pearson N, Biddle SJ \& Gorely T (2009) Family correlates of fruit and vegetable consumption in children and adolescents: a systematic review. Public Health Nutr 12, 267-283.

14. Raynor HA, Polley BA, Wing RR et al. (2004) Is dietary fat intake related to liking or household availability of highand low-fat foods? Obes Res 12, 816-823.

15. Larson NI, Story M, Eisenberg ME et al. (2006) Food preparation and purchasing roles among adolescents: associations with sociodemographic characteristics and diet quality. J Am Diet Assoc 106, 211-218.

16. Larson NI, Perry CL, Story M et al. (2006) Food preparation by young adults is associated with better diet quality. $J \mathrm{Am}$ Diet Assoc 106, 2001-2007.

17. Clifford D, Anderson J, Auld G et al. (2009) Good Grubbin': impact of a TV cooking show for college students living off campus. J Nutr Educ Behav 41, 194-200.

18. Cullen KW, Watson KB, Zakeri I et al. (2007) Achieving fruit, juice, and vegetable recipe preparation goals influences consumption by 4 th grade students. Int J Behav Nutr Phys Act 4, 28.

19. Condrasky M, Graham K \& Kamp J (2006) Cooking with a Chef: an innovative program to improve mealtime practices and eating behaviors of caregivers of preschool children. J Nutr Educ Behav 38, 324-325.

20. Beets MW, Swanger K, Wilcox DR et al. (2007) Using hands-on demonstrations to promote cooking behaviors with young adolescents: the Culinary Camp summer cooking program. J Nutr Educ Behav 39, 288-289.

21. Fulkerson JA, Rydell S, Kubik MY et al. (2010) Healthy Home Offerings via the Mealtime Environment (HOME): feasibility, acceptability, and outcomes of a pilot study. Obesity (Silver Spring) 18, Suppl. 1, S69-S74.

22. Engler-Stringer R (2010) Food, cooking skills, and health: a literature review. Can J Diet Pract Res 71, 141-145.

23. Neumark-Sztainer D, Story M, Hannan PJ et al. (2002) Overweight status and eating patterns among adolescents: where do youths stand in comparison with the healthy people 2010 objectives? Am J Public Health 92, 844-851.

24. Neumark-Sztainer D, Croll J, Story M et al. (2002) Ethnic/ racial differences in weight-related concerns and behaviors among adolescent girls and boys: findings from Project EAT. J Psychosom Res 53, 963-974.

25. Neumark-Sztainer D, Wall M, Guo J et al. (2006) Obesity, disordered eating, and eating disorders in a longitudinal study of adolescents. J Am Diet Assoc 106, 559-568.
26. Neumark-Sztainer D, Wall M, Eisenberg ME et al. (2006) Overweight status and weight control behaviors in adolescents: longitudinal and secular trends from 1999 to 2004. Prev Med 43, 52-59.

27. Larson N, Neumark-Sztainer D, Harwood EM et al. (2011) Do young adults participate in surveys that 'go green'? Response rates to a web and mailed survey of weightrelated health behaviors. Int J Child Health Hum Dev $\mathbf{4}$, 225-237.

28. Neumark-Sztainer D, Wall M, Larson NI et al. (2011) Disordered eating behaviors from adolescence to young adulthood: findings from a 10-year longitudinal study. $\mathrm{J} \mathrm{Am}$ Diet Assoc 111, 1004-1011.

29. Harvard School of Public Health, Nutrition Department (2007) HSPH Nutrition Department's File Download Site. https://regepi.bwh.harvard.edu/health/nutrition.html (accessed January 2008).

30. Feskanich D, Rimm E, Giovannucci E et al. (1993) Reproducibility and validity of food intake measurements from a semiquantitative food frequency questionnaire. J Am Diet Assoc 93, 790-796.

31. Rimm E, Giovannucci E, Stampfer M et al. (1992) Reproducibility and validity of an expanded self-administered semiquantitative food frequency questionnaire among male health professionals. Am J Epidemiol 135, 1114-1126.

32. Rockett HR, Breitenbach M, Frazier AL et al. (1997) Validation of a youth/adolescent food frequency questionnaire. Prev Med 26, 808-816.

33. Rockett HR, Wolf AM \& Colditz GA (1995) Development and reproducibility of a food frequency questionnaire to assess diets of older children and adolescents. J Am Diet Assoc 95, 336-340.

34. Little R (1986) Survey nonresponse adjustments for estimates of means. Int Stat Rev 54, 137-139.

35. US Census Bureau (2011) American Community Survey, 2007-2009; Detailed tables B01001A-I, B17001. http://factfinder. census.gov/ (accessed September 2011).

36. Eisenberg ME, Berge J, Fulkerson JA et al. (2011) Weight comments by family and significant others in young adulthood. Body Image 8, 12-19.

37. Laska MN, Graham D, Moe S et al. (2010) Situational characteristics of young adult eating occasions: a real-time data collection using Personal Digital Assistants. Public Health Nutr (Epublication ahead of print version).

38. Lichtenstein AH \& Ludwig DS (2010) Bring back home economics education. JAMA 303, 1857-1858.

39. Werhan C \& Way W (2006) Family and consumer sciences programs in secondary schools: results of a national survey. J Fam Consum Sci 98, 19-25.

40. Centers for Disease Control and Prevention (2010) Statespecific trends in fruit and vegetable consumption among adults - United States, 2000-2009. MMWR Morb Mortal Wkly Rep 59, 1125-1130.

41. Winkler E \& Turrell G (2009) Confidence to cook vegetables and the buying habits of Australian households. J Am Diet Assoc 109, 1759-1768.

42. Smith KJ, McNaughton SA, Gall SL et al. (2010) Involvement of young Australian adults in meal preparation: crosssectional associations with sociodemographic factors and diet quality. J Am Diet Assoc 110, 1363-1367.

43. Nelson MC, Kocos R, Lytle LA et al. (2009) Understanding the perceived determinants of weight gain in late adolescence: a qualitative analysis among college youth. J Nutr Educ Behav 41, 287-292.

44. Dietary Guidelines Advisory Committee (2010) Report of the Dietary Guidelines Advisory Committee on the Dietary Guidelines for Americans. http://www.cnpp.usda.gov/dgas 2010-dgacreport.htm (accessed July 2010). 